\title{
Predictive and Prognostic Factors for the Outcome of the Patients Receiving Pegylated Liposomal Doxorubicin for Advanced Breast Cancer
}

\author{
Salah Mabrouk Khallaf* (1), Jasmine Roshdy, Abeer Ibrahim \\ Medical Oncology Department, South Egypt Cancer Institute, Assiut University, Assiut, Egypt \\ Email: *salahmab76@yahoo.com
}

How to cite this paper: Khallaf, S.M., Roshdy, J. and Ibrahim, A. (2020) Predictive and Prognostic Factors for the Outcome of the Patients Receiving Pegylated Liposomal Doxorubicin for Advanced Breast Cancer. Advances in Breast Cancer Research, 9, 21-33.

https://doi.org/10.4236/abcr.2020.92003

Received: March 8, 2020

Accepted: April 7, 2020

Published: April 10, 2020

Copyright $\odot 2020$ by author(s) and Scientific Research Publishing Inc. This work is licensed under the Creative Commons Attribution International License (CC BY 4.0).

http://creativecommons.org/licenses/by/4.0/

\begin{abstract}
Purpose: The treatment of advanced breast cancer $(A B C)$ is still challenging aiming mainly to improve or maintain the quality of life. The efficacy of pegylated liposomal doxorubicin (PLD) was proven in patients with $\mathrm{ABC}$. Because its expensive treatment there is a great need to find the predictive factors for the clinical outcome of PLD. Our purpose was to evaluate the factors which would affect the clinical outcomes in patients receiving PLD for advanced breast cancer. Methods: Retrospectively, we studied the medical records of 60 eligible patients during the period of seven years (Jan. 2011-Dec. 2017). All patients were treated in Medical Oncology Department, South Egypt Cancer Institute, Assiut University, Egypt. We included only patients with visceral metastasis who received at least 2 cycles of PLD and had radiological assessment after that. Clinical benefit rate of PLD and survival outcome were assessed and correlated with patients and disease characteristic. Results: The majority of patients had a performance status grade II (81.7\%), recurrent disease (86.7\%), more than one metastatic site $(83.3 \%)$, and chemoresistance to previous anthracycline $(75 \%)$. The clinical benefit rate (CBR) to PDL was $30 \%$. We found statistical significant association between higher CBR and biological subtypes ( $p<0.001)$, type of metastatic breast disease $(p=0.003)$, chemosensitivity to anthracycline $(\mathrm{p}<0.001)$, and the number of previous lines of chemotherapy ( $\mathrm{p}=0.041$ ). The median progression-free survival (PFS) was five months. There was a statistically-significant improvement of PFS among patients with anthracycline-sensitive tumors compared to those with anthracycline-resistant tumors (10 months vs. 5 months, respectively, $\mathrm{p}=0.004$ ). The most common toxicity was palmar-plantar erythrodysesthesia (28\% for all grade and $9 \%$ for grade 3 or more). There was no severe cardiotoxicity or treatment-related death.
\end{abstract}


Conclusion: Pegylated liposomal doxorubicin appears to be more effective in patients with (luminal B with Her2neu positive, triple-negative and in her2neu amplified), also we noticed that de novo metastatic disease, patient who are not heavily pretreated tumors and patients with the anthracycline-sensitive tumor get more benefit from PLD than others.

\section{Keywords}

Metastatic Breast, Pegylated Liposomal Doxorubicin, De Novo, Biological Subtypes, Chemosensitivity

\section{Introduction}

Globally, breast cancer is the most-common cancer in women after skin cancer [1]. Breast cancer is responsible for about $13.7 \%$ of cancer deaths in women worldwide [2]. This mortality is mainly related to metastatic or advanced disease [3].

The treatment of $\mathrm{ABC}$ is still challenging and mainly aiming to improve or maintain the quality of life, relieve the symptoms, and, to a lesser extent, improving the disease-related survivals [4].

There is no standard of care for $\mathrm{ABC}$ management; however, chemotherapy is a treatment option for many patients with ABC. Doxorubicin considered among the most active agents in [5].

Unfortunately, this known efficacy of doxorubicin in $\mathrm{ABC}$ is countered by its dose-limiting myelosuppression and cardiotoxicity [6] [7]. Myelosuppression may be life-threatening when sepsis occurs due to neutropenia that reaches its nadir 10 to 14 days after treatment [8]. The incidence of the cardiotoxicity is proportionally related to lifetime cumulative dose of doxorubicin which should not exceed $450-500 \mathrm{mg} / \mathrm{m}^{2}$ [9] [10] [11].

Pegylated liposomal doxorubicin (PLD) was manufactured through capsulation of doxorubicin with polyethylene glycol-coated liposome. This results in a new pharmacokinetic criterion; that PLD is restricted to the vascular space in the tissues having tight capillary junctions, such as the cardiac muscle and gastrointestinal tract. PLD can penetrate fenestrations of the vascular wall where its endothelial cells are either not tightly joined or disrupted by inflammation or tumor growth. Thus, PLD has less concentration at cardiac muscle and gastrointestinal tract which are the sites of its potential toxicity and more concentration at the tumor tissue resulting in lesser toxicity (cardiotoxicity, myelosuppression, and alopecia) and more or, at a lesser extent, equal efficacy when compared with conventional doxorubicin [12]-[17].

The dose-limiting toxicity of PLD is the palmar-plantar erythrodysesthesia (PPE), also known as a hand-foot syndrome [8] [17] [18] [19].

The efficacy of PLD was proven in patients with ABC [6] [7] [9] [10] [11] [20] 
[21]. Still, there is a great need to find the predictive factors for the clinical outcome of PLD in those patients. We conducted this retrospective study to find the possible predictive factors for the outcomes in those patients receiving PLD.

\section{Methods}

\subsection{Study Design}

This retrospective study was based on the examination of the medical hospital records of patients with evidence of $\mathrm{ABC}$ during the period of seven years (January 2011 to December 2017). All patients were treated in Medical Oncology Department, South Egypt Cancer Institute, Assiut University, Egypt. We included patients with visceral metastatic breast cancer who had received at least 2 cycles of PLD. And the assessment of their response to PLD was done at least once. The exclusion criteria included any of the following items: double malignancy other than bilateral breast cancer, PLD was received as doublet, or patients missed without assessment.

PLD was given as $50 \mathrm{mg} / \mathrm{m}^{2}$ over a 30 - or 60 -minute intravenous infusion on day 1 . The cycle frequency was every 4 weeks. It was given until maximal response, unacceptable toxicity, or patient preference to discontinue.

Patients were categorized into subgroups based on demographics and characteristics of their tumor. Demographics' subgroups were age-related (65 years or more vs. less than 65 years old), Eastern Cooperative Oncology Group performance status (grade 0/I vs. II), menopausal status (pre/perimenopausals vs. postmenopausals). While the subgroups according to tumors' characteristics were pathological type (IDC vs. ILC vs. Others), tumor grade (grade I/II vs. III), biological subtype (luminal A vs. luminal B \& her2 -ve vs. Luminal B \& her2 +ve vs. Her2 amplified vs. triple-negative), type of metastasis (de novo $A B C$ vs. recurrent $\mathrm{ABC}$ ), number of metastasized organ/s (one vs. two or more), the order of PLD line (the $3^{\text {rd }}$ palliative vs. the $4^{\text {th }}$ palliative or more), and chemosensitivity to previous anthracycline (chemosensitive vs. chemoresistant tumors). These variables were chosen based on the previous studies [6] [7] [9] [10] [11] [20] [21].

\subsection{Subgroups Categorization of Patients}

We categorized patient according to St. Gallen classification system into five groups (Table 1) [22]. Also we categorized the patients according to anthracycline sensitivity into a) Anthracycline-resistance group, are those patients who had progression occurs during the anthracycline therapy when recurrence occurs within 12 months after the last curative cycle of anthracycline based regimen or within 6 months after the last palliative anthracycline cycle for patients who achieved complete remission. While the anthracycline-sensitive tumor (also called anthracycline-non-resistant) are those patients who didn't fulfil the previous criteria of the chemoresistant tumor were not fulfilled [21]. 
Table 1. Definition of subtypes of breast cancer-St. Gallen classification [22].

\begin{tabular}{cccc}
\hline Breast cancer subtypes & Er and Pr & Her-2 & Ki67 \\
\hline Luminal a & Er+ and/or pr+ & Her-2- & Ki67 $<14 \%$ \\
Luminal b with her-2 negative & Er+ and/or pr+ & Her-2- & Ki-67 $\geq 14 \%$ \\
Luminal b with her-2 positive & Er+ and/or pr+ & Her-2+ & Any ki-67 \\
Her-2 enriched & Er-, pr- & Her-2+ & Any ki-67 \\
Basal-like (triple-negative) & Er-, pr- & Her-2- & Ck5/6+ and/or EGFR+ \\
\hline
\end{tabular}

Abbreviations: CK 5/6: cytokeratin 5/6; EGFR: epidermal growth factor receptors; Er: estrogen receptors; Pr: progesterone receptors.

\subsection{Statistical Analysis}

The primary endpoints were a) Clinical Benefit Rate (CBR); which defined as percentage of patients who have complete response [CR], partial response [PR] or stable disease [SD] for more than 6 months [23]. b) Progression-free survival (PFS); defined as the time from the start of treatment to disease progression, death from any cause, or date of last follow up, whichever came first).

The secondary endpoint was overall survival (OS) which defined as the time from the start of treatment to date of death from any cause, or date of last follow up, whichever came first). Assessment toxicity profile was based on the Common Terminology Criteria for Adverse Events (CTCAE) [24]. Continuous variables were presented as median and range. Categorical variables (nominal and ordinal) are presented as frequency and percentage. Bivariate analysis was done to compare categorical variables using the Chi-Square test. Kaplan-Meier method was used to estimate the survival time. Cox regression analysis was used for the multivariate analysis. p-value less than 0.05 was considered a significant value. SPSS version 21.0 (SPSS Inc. Chicago, IL, USA) was used in the storage and analysis of data [25].

\section{Results}

\subsection{Patients' Demographics and Tumor Characteristics}

Sixty eligible patients were analyzed for results. Table 2 shows that the majority (95\%) were adults (less than 65 years). Most patients (81.7\%) had a performance status of grade II. About one third (30\%) of the patients were postmenopausal. The most common biological type was luminal A (41.7\%), then triple-negative type (36.7\%). De novo $\mathrm{ABC}$ incidence (13.3\%) was less than recurrent $\mathrm{ABC}$ (86.7\%). Fifty out of the studied patients had more than one metastatic organ.

Sixteen patients $(26.7 \%)$ received PLD as the $3^{\text {rd }}$ line palliative after the previous anthracycline and taxanes lines, while the remaining (73.3\%) received it as $4^{\text {th }}$ line or beyond that. Three quarters $(75 \%)$ of our patients had tumors that were chemoresistant to previous anthracyclines (doxorubicin or epirubicin). 
Table 2. Patients' demographics and tumor characteristics.

\begin{tabular}{|c|c|c|c|}
\hline Characteristic & $\mathbf{N}^{\bullet}$ & & $\%$ \\
\hline \multicolumn{4}{|l|}{ Age (years) } \\
\hline Median & \multicolumn{3}{|c|}{45} \\
\hline Range & \multicolumn{3}{|c|}{$28-65$} \\
\hline \multicolumn{4}{|l|}{ Age group (years) } \\
\hline$<65$ & 57 & & 95.0 \\
\hline$\geq 65$ & 3 & & 5.0 \\
\hline \multicolumn{4}{|l|}{ ECOG PS } \\
\hline $0, \mathrm{I}$ & 11 & & 18.3 \\
\hline II & 49 & & 81.7 \\
\hline \multicolumn{4}{|l|}{ Menopausal status } \\
\hline Pre/perimenopausal & 42 & & 70.0 \\
\hline Postmenopausal & 18 & & 30.0 \\
\hline \multicolumn{4}{|l|}{ Pathological type } \\
\hline IDC & 52 & & 86.7 \\
\hline ILC & 6 & & 10.0 \\
\hline Others & 2 & & 3.3 \\
\hline \multicolumn{4}{|l|}{ Tumor Grade } \\
\hline Grade I or II & 54 & & 90.0 \\
\hline Grade III & 6 & & 10.0 \\
\hline \multicolumn{4}{|l|}{ Biological subtype } \\
\hline Luminal A & 25 & & 41.7 \\
\hline Luminal B \& her2 -ve & 5 & & 8.3 \\
\hline Luminal B \& her2 +ve & 0 & & 0.0 \\
\hline Her2 amplified & 8 & & 13.3 \\
\hline Triple-negative & 22 & & 36.7 \\
\hline \multicolumn{4}{|l|}{ Type of metastasis } \\
\hline Denovo ABC & 8 & & 13.3 \\
\hline Recurrent $\mathrm{ABC}$ & 52 & & 86.7 \\
\hline \multicolumn{4}{|l|}{ No of metastasized organ/s } \\
\hline One & 10 & & 16.6 \\
\hline Two or more & 50 & & 83.4 \\
\hline \multicolumn{4}{|l|}{ Order of PLD line } \\
\hline $3^{\text {rd }}$ palliative & 16 & & 26.7 \\
\hline $4^{\text {th }}$ palliative or more & 44 & & 73.3 \\
\hline \multicolumn{4}{|l|}{ Chemosensitivity } \\
\hline Chemosensitive & 15 & & 25.0 \\
\hline Chemoresistant & 45 & & 75.0 \\
\hline \multicolumn{4}{|l|}{ Chemotherapy cycles } \\
\hline Total number & & 296 & \\
\hline Mode & & 3 & \\
\hline Range & & $3-18$ & \\
\hline
\end{tabular}

Abbreviations: ECOG PS, Eastern Cooperative Oncology Group performance status; IDC, invasive ductal carcinoma; ILC, infiltrating lobular carcinoma; Her 2, human epidermal growth factor receptor 2. 


\subsection{Response Rates}

There was no case of complete response (CR). Five cases (8.3\%) developed partial remission, while thirteen cases $(21.7 \%)$ had stable disease for more than six months. Forty-two cases (70\%) had progressive disease. From previous results, CBR was $30 \%$. Four factors significantly affected CBR. The very high significant value appeared within biological subtypes; all cases (100\%) with luminal B with her2 positive subtype were stable on PLD, while CBR for patients with TNBC and HER 2 amplified disease were $40.9 \%$ and $37.5 \%$, respectively $(\mathrm{p}<0.001)$. $\mathrm{CBR}$ in patients with de novo $\mathrm{ABC}$ was about three times higher than in patients with recurrent $\mathrm{ABC}$ ( $75 \%$ vs. $23.1 \%$ respectively; $\mathrm{p}=0.003)$. Patients with the chemosensitive disease had a significantly higher CBR when compared to those with the chemoresistant disease ( $66.7 \%$ vs. $17.8 \%$ respectively; $\mathrm{p}<0.001)$. PLD given as the $3^{\text {rd }}$ line achieved higher CBR than when it given as the $4^{\text {th }}$ line or more $(50.0 \%$ vs. $22.7 \%$ respectively; $\mathrm{p}=0.041)$.

\subsection{Survival Outcome}

The median PFS was five months; 95\% CI 4.05 - 5.94 months (Figure 1). Chemosensitivity to the previous anthracycline is the only factor that significantly affected the PFS; The median PFS was twice as long for patients with chemosensitive tumor compared to those with chemoresistant tumor (10 months; $95 \%$ CI 5.31 - 14.68 versus 5 months; 95\% CI 4.20 - 5.79 respectively; $\mathrm{p}=004$ ) (Figure 2).

The median OS was 11 months, with $95 \%$ CI of $9.48-12.51$ months (Figure 3). Our results demonstrated that there was no significant effect of the studied factor on OS.

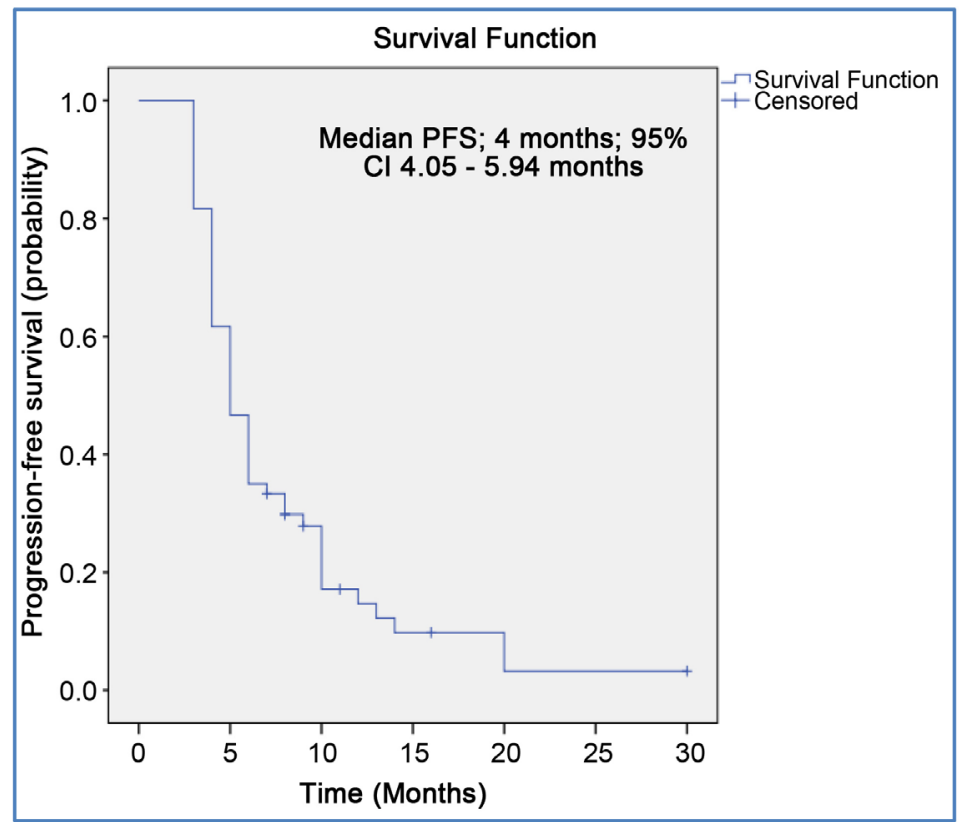

Figure 1. Kaplan-meier plot: progression-free survival. CI: confidence interval; PFS: progression-free survival. 


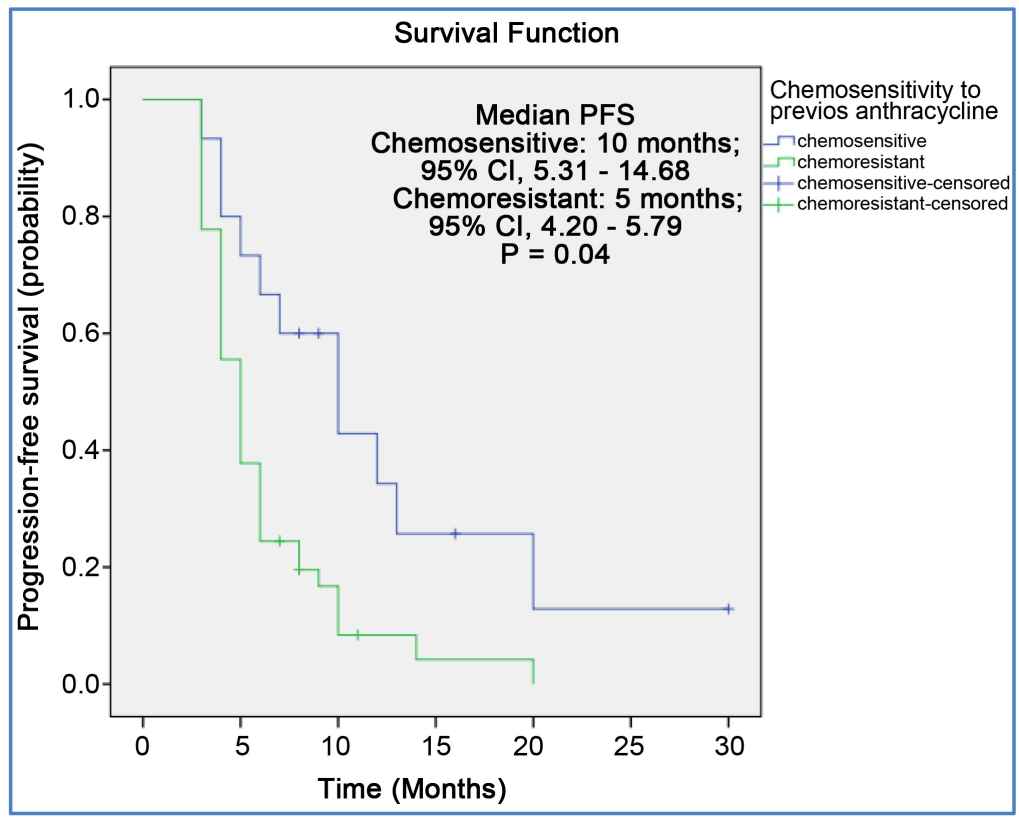

Figure 2. Kaplan-meier plot: progression-free survival according to chemosensitivity to previous anthracycline. CI: confidence interval; PFS: progression-free survival.

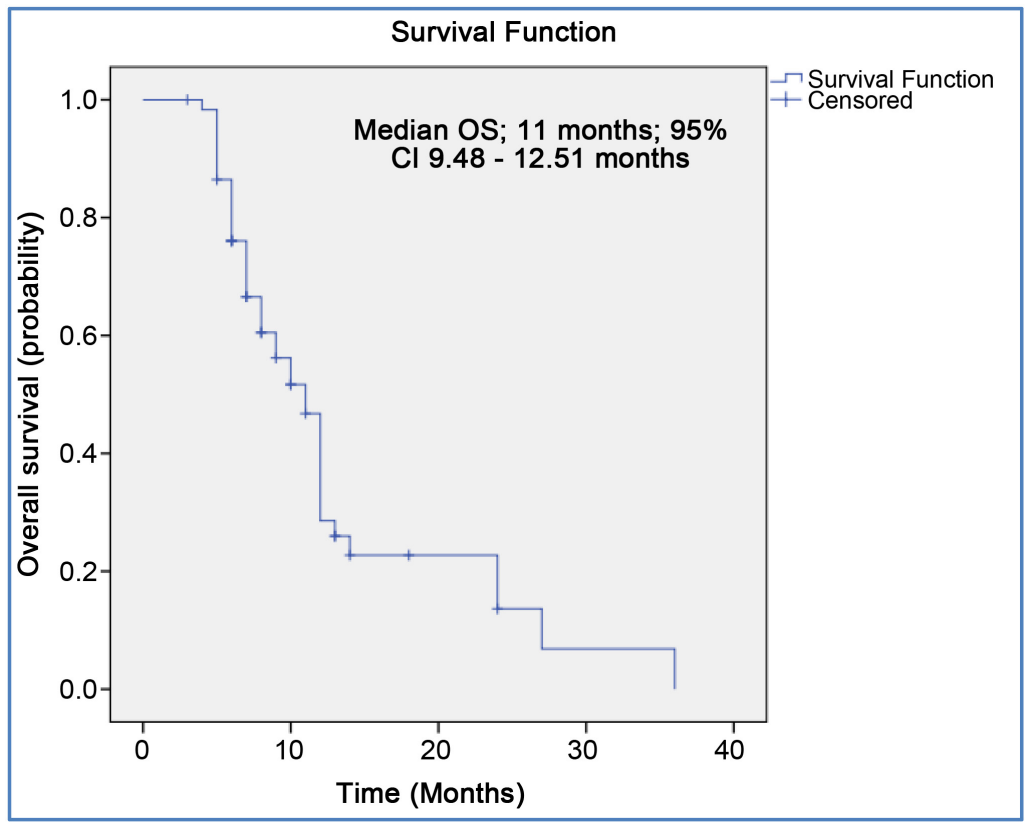

Figure 3. Kaplan-Meier plot: Overall survival. CI: confidence interval; OS: overall survival.

\subsection{Adverse Effects}

All cases received 296 cycles of PLD (range 3 - 18). The dose reductions were required in eight cases (13.3\%), while four cases (6.7\%) could not tolerate PLD due to PPE (2 cases), stomatitis (one case), and hypersensitivity (one case). As shown in Table 3, the majority of adverse effects were of low grades. PPE was 
Table 3. Toxicity of pegylated liposomal doxorubicin in the studied patients $(\mathrm{N}=60)$.

\begin{tabular}{ccc}
\hline Event & $\begin{array}{c}\text { All grades } \\
\text { No (\%) }\end{array}$ & $\begin{array}{c}\text { Grade III/IV } \\
\text { No (\%) }\end{array}$ \\
\hline Non-hematological & $17(28)$ & $5(9)$ \\
PPE & $15(25)$ & $4(7)$ \\
Stomatitis & $10(17)$ & $3(5)$ \\
Diarrhea & $9(15)$ & $2(4)$ \\
Fatigue & $8(13.3)$ & $1(2)$ \\
Anorexia & $7(12)$ & $1(2)$ \\
Nausea & $7(12)$ & $2(4)$ \\
Hypersensitivity & $6(10)$ & $1(2)$ \\
Asthenia & $5(9)$ & $1(2)$ \\
Constipation & $2(4)$ & $0(0)$ \\
Cardiac toxicity & & $2(4)$ \\
Hematological & $10(17)$ & $3(5)$ \\
Anemia & $4(7)$ & $2(4)$ \\
Neutropenia & $3(5)$ & $0(0)$ \\
Leukopenia & $2(4)$ & \\
Thrombocytopenia & & $2(4)$ \\
\hline
\end{tabular}

Abbreviation: PPE: palmar-plantar erythrodysesthesia.

the most common non-hematological toxicity (28\%) followed by stomatitis (25\%) then diarrhea (17\%), while neutropenia (5\%) was the most common hematological toxicity, followed by anemia and leukopenia ( $4 \%$ for each adverse effect). No reported cases for severe cardiac toxicity. Also, there was no treatment-related death.

\section{Discussion}

In this retrospective study that included 60 patients with ABC received PLD. After data analysis, we found that $\mathrm{CBR}$ was $30 \%$, with four among the investigated factors had a significant effect on $\mathrm{CBR}$ : biological subtypes, type of $\mathrm{ABC}$, chemosensitivity, and order of PLD line.

We stated that the luminal B subtype had the best CBR, followed by TNBC, then HER2 amplified, and then the lowest CBR for luminal A (100\%, 40.9\%, $37.5 \%$, and $4 \%$ respectively; $\mathrm{p}=0.000$ ). To best of our knowledge, no study addressed the effect of biological subtypes on CBR in patients received PLD as single agent for ABC; however, Fabi et al. [26] conducted a phase II clinical trial to determine the clinical efficacy and safety of PLD in combination with gemcitabine as a first- or second-line treatment option in patients with $A B C$. They reported that HER2 overexpression predicted response to PLD in ABC patients (CBR; 84.3\% for patients with HER2-positive tumors vs. $74 \%$ for patients with HER2-positive tumors) [26]. CBR is higher than that of our study (37.5\%); this may be due to 
the high percentage of chemoresistant (75\%) and luminal A (41.7\%) subgroups and low percentage $(13.3 \%)$ of her 2 amplified subgroup within our patients (Table 2).

CBR in patients with de novo $\mathrm{ABC}$ was about three times higherthan in patients with recurrent $\mathrm{ABC}$ ( $75 \%$ vs. $23.1 \%$ respectively; $\mathrm{p}=0.003)$. To the best of our knowledge, there is no previous work on this topic regarding PLD.

As regards to the chemotherapy-related factors, patients with chemosensitive disease had about four times CBR higher than in patients with chemoresistant disease; $(66.7 \%$ vs. $17.8 \%$; $\mathrm{p}=0.0001)$. Also, when PLD was given as the $3^{\text {rd }}$ line, CBR was higher than when given as the 4 th line or more $(50.0 \%$ vs. $22.7 \%$ respectively; $\mathrm{p}=0.041$ ). Aphase III German study conducted by Al-Batran et al. [13] and an Austrian observational trial conducted by Fiegl et al. [27] studied these factors. Al-Batran et al. showed slightly less CBR than that our study (24\% vs. $30 \%$ respectively). In agreement with our data, this German study [13] revealed that the patients not heavily pretreated had higher CBR than those heavily pretreated $(30 \%, 21.7 \%, 19.2 \%$ for patients received one, two, and three more previous regimen/s respectively). Also, Austrian observational [27] trial proved the same conclusion (overall response rate [ORR]; 32\% for patients received up to three previous regimens vs. $12 \%$ for patients received four or more previous regimens; $\mathrm{p}=0.024)$. In contrast with our result, Al-Batran et al. [13] documented that chemosensitivity had an insignificant effect on CBR $(16.1 \%$ in patients with anthracycline-resistant disease $v s .29 \%$ in non-anthracycline-resistant patients; $p$ $=0.186)$, it may be due to different definitions of the chemosensitivity between two studies; they defined anthracycline resistance when patients had disease progression on anthracycline therapy for $\mathrm{ABC}$ or within 6 months of adjuvant therapy.

The median PFS for our patients was five months (95\% CI 4.05 - 5.94 months), which is slightly more than that stated by Al-Batran et al. [13] (3.6 months; 95\% CI 2.7 - 6.4). In our study, the chemosensitivity was the only significant predictive factor for the median PFS (10 months; 95\% CI, 5.31 to 14.68 for patients with chemosensitive tumor versus 5 months; $95 \%$ CI, 4.20 to 5.79 for those with chemoresistant tumor; $\mathrm{p}=004)$. Data about the effect of chemosensitivity on PFS for patients receiving PLD is still lacking. Only two studies addressed that issue, but without details or direct conclusion. These two studies agree with our findings. The first one is conducted by Al-Batran et al. [13] who reported patients with a non-anthracycline-resistant disease has a higher PFS than those having an anthracycline-resistant disease; however, P-value was not reported. The second trial reported by Keller et al. [17] who indirectly confirmed the same finding. They stated that PLD has a superior PFS compared to vinorelbine in the patients with non-anthracycline-resistant disease (3.7 vs. 2.6 months respectively), but in patients with anthracycline-resistant ABC, the median PFS is comparable (2.6 months for each group).

Median OS of our patients was 11 months (95\% CI 9.48 - 12.51 months), 
which is slightly less than that documented by Al-Batran et al. [13] (12.3 months; 95\% CI 7.7 - 16.3). All investigated factors in our study had no any significant effect on the median OS. In contrast with our study, Fiegl et al. [27] reported that the occurrence of a greater number $(\geq 4)$ of metastatic sites was the only independent risk factor for shorter OS (hazard ratio, 2.78; 95\% CI, $1.75-4.42$; p < $0.001)$.

We do not report any case of severe cardiac toxicity. This is matching with previous studies published by Al-Batran et al. [13], Keller et al. [17], and Basso et al. [28] and likely similar results of studies conducted by Harbeck et al. [29] and Huober et al. [20] who reported that the incidence of severe cardiac toxicity was about $1 \%$. We recorded that PPE was the most common adverse effect $(28 \%$ for all grades and $9 \%$ for grade $3 / 4$ toxicities). The occurrence of grade $3 / 4 \mathrm{PPE}$ in our study is slightly nearby the results documented by Al-Batran et al. (6.4\%) [13], Basso et al. (6.3\%) [28], and Huober et al. (6.0\%) [20], and greatly lower than that the incidence reported by Harbeck et al. (39\%) [29] and Keller et al. (19\%) [17]. Fiegl et al. [27] documented only 1\% grade 3/4 PPE. This variance in occurrence of PPE may be due to different biological criteria of the patients, different dosage per cycles, and different cumulative dose of PLD received by every patient.

The main limitations of our study are its retrospective nature and a relatively small number of sample size. Also, the PLD was given beyond previous two lines of palliative chemotherapy. We recommend a further prospective study including the larger sample size, with PLD given as a frontline therapy.

\section{Conclusion}

Pegylated liposomal doxorubicin appears to be more effective in patients' subgroups with specific tumor criteria including special biological subtypes (luminal B with human epidermal growth factor receptor 2 positive, triple-negative, and her2 amplified), de novo metastatic disease, not heavily pretreated tumors, and the anthracycline-sensitive tumor. Therefore, patients selection should be considered.

\section{Conflicts of Interest}

The authors declare no conflicts of interest regarding the publication of this paper.

\section{Ethical Approval}

This article does not contain any studies with animals performed by any of the authors. All procedures performed in studies involving human participants were in accordance with the ethical standards of the institutional and/or national research committee and with the 1964 Helsinki declaration and its later amendments or comparable ethical standards. 


\section{References}

[1] McGuire, A., Brown, J.A., Malone, C., McLaughlin, R. and Kerin, M.J. (2015) Effects of Age on the Detection and Management of Breast Cancer. Cancers, 7, 908-929. https://doi.org/10.3390/cancers7020815

[2] International Agency for Research on Cancer (2008) World Cancer Report.

[3] Howlader, N., Noone, A.M., Krapcho, M., et al. (2019) SEER Explorer. Breast Cancer-Stage Distribution of SEER Incidence Cases, 2007-2016 by Sex. National Cancer Institute, Bethesda.

[4] O’Shaughnessy, J. (2005) Extending Survival with Chemotherapy in Metastatic Breast Cancer. The Oncologist, 10, 20-29.

https://doi.org/10.1634/theoncologist.10-90003-20

[5] Gralow, J.R. (2005) Optimizing the Treatment of Metastatic Breast Cancer. Breast Cancer Research and Treatment, 89, S9-S15. https://doi.org/10.1007/s10549-005-0143-Z

[6] Polovich, M., White, J.M. and Kelleher, L.O. (2005) Chemotherapy and Biotherapy Guidelines and Recommendations for Practice. 2nd Edition, Oncology Nursing Society, Pittsburgh.

[7] Rivera, E. (2003) Liposomal Anthracyclines in Metastatic Breast Cancer: Clinical Update. Oncologist, 8, 3-9. https://doi.org/10.1634/theoncologist.8-suppl_2-3

[8] Barrett-Lee, P.J., Dixon, J.M., Farrell, C., Jones, A., Leonard, R., Murray, N., Palmieri, C., Plummer, C.J., Stanley, A. and Verrill, M.W. (2009) Expert Opinion on the Use of Anthracyclines in Patients with Advanced Breast Cancer at Cardiac Risk. Annals of Oncology: Official Journal of the European Society for Medical Oncology/ESMO, 20, 816-827. https://doi.org/10.1093/annonc/mdn728

[9] McGowan, J.V., Chung, R., Maulik, A., Piotrowska, I., Walker, J.M. and Yellon, D.M. (2017) Anthracycline Chemotherapy and Cardiotoxicity. Cardiovascular Drugs and Therapy, 31, 63-75. https://doi.org/10.1007/s10557-016-6711-0

[10] Xing, M., Yan, F., Yu, S. and Shen, P. (2015) Efficacy and Cardiotoxicity of Liposomal Doxorubicin-Based Chemotherapy in Advanced Breast Cancer: A Meta-Analysis of Ten Randomized Controlled Trials. PLoS ONE, 10, e0133569. https://doi.org/10.1371/journal.pone.0133569

[11] Simunek, T., Sterba, M., Popelova, O., Adamcova, M., Hrdina, R. and Gersl, V. (2009) Anthracycline-Induced Cardiotoxicity: Overview of Studies Examining the Roles of Oxidative Stress and Free Cellular Iron. Pharmacological Reports, 61, 154-171. https://doi.org/10.1016/S1734-1140(09)70018-0

[12] Mlineritsch, B., Mayer, P., Rass, C., Reiter, E., Russ, G., Vesenmayer, G., Oberaigner, W. and Hausmaninger, H. (2004) Phase II Study of Single-Agent Pegylated Liposomal Doxorubicin HCl (PLD) in Metastatic Breast Cancer after First-Line Treatment Failure. Onkologie, 27, 441-446. https://doi.org/10.1159/000080363

[13] Al-Batran, S.E., Bischoff, J., von Minckwitz, G., Atmaca, A., Kleeberg, U., Meuthen, I., Morack, G., Lerbs, W., Hecker, D., Sehouli, J., Knuth, A. and Jager, E. (2006) The Clinical Benefit of Pegylated Liposomal Doxorubicin in Patients with Metastatic Breast Cancer Previously Treated with Conventional Anthracyclines: A Multicentre Phase II Trial. British Journal of Cancer, 94, 1615-1620.

https://doi.org/10.1038/sj.bjc.6603158

[14] Ranson, M.R., Carmichael, J., O’Byrne, K., Stewart, S., Smith, D. and Howell, A. (1997) Treatment of Advanced Breast Cancer with Sterically Stabilized Liposomal Doxorubicin: Results of a Multicenter Phase II Trial. Journal of Clinical Oncology, 15, 3185-3191. https://doi.org/10.1200/JCO.1997.15.10.3185 
[15] Lyass, O., Uziely, B., Ben-Yosef, R., Tzemach, D., Heshing, N.I., Lotem, M., Brufman, G. and Gabizon, A. (2000) Correlation of Toxicity with Pharmacokinetics of Pegylated Liposomal Doxorubicin (Doxil) in Metastatic Breast Carcinoma. Cancer, 89, 1037-1047. https://doi.org/10.1002/1097-0142(20000901)89:5<1037::AID-CNCR13>3.0.CO;2-Z

[16] O’Brien, M.E., Wigler, N., Inbar, M., Rosso, R., Grischke, E., Santoro, A., Catane, R., Kieback, D.G., Tomczak, P., Ackland, S.P., Orlandi, F., Mellars, L., Alland, L. and Tendler, C. (2004) CAELYX Breast Cancer Study Group. Reduced Cardiotoxicity and Comparable Efficacy in a Phase III Trial of Pegylated Liposomal Doxorubicin $\mathrm{HCl}$ (CAELYX/Doxil) versus Conventional Doxorubicin for First-Line Treatment of Metastatic Breast Cancer. Annals of Oncology, 15, 440-449. https://doi.org/10.1093/annonc/mdh097

[17] Keller, A.M., Mennel, R.G., Georgoulias, V.A., Nabholtz, J.M., Erazo, A., Lluch, A., Vogel, C.L., Kaufmann, M., von Minckwitz, G., Henderson, I.C., Mellars, L., Alland, L. and Tendler, C. (2004) Randomized Phase III Trial of Pegylated Liposomal Doxorubicin versus Vinorelbine or Mitomycin C plus Vinblastine in Women with Taxane-Refractory Advanced Breast Cancer. Journal of Clinical Oncology, 22, 3893-3901. https://doi.org/10.1200/JCO.2004.08.157

[18] Coleman, R.E., Biganzoli, L., Canney, P., Dirix, L., Mauriac, L., Chollet, P., Batter, V., Ngalula-Kabanga, E., Dittrich, C. and Piccart, M. (2006) A Randomised Phase II Study of Two Different Schedules of Pegylated Liposomal Doxorubicin in Metastatic Breast Cancer (EORTC-10993). European Journal of Cancer, 42, 882-887. https://doi.org/10.1016/j.ejca.2005.12.011

[19] Lorusso, D., Di Stefano, A., Carone, V., Fagotti, A., Pisconti, S. and Scambia, G. (2007) Pegylated Liposomal Doxorubicin-Related Palmar-Plantar Erythrodysesthesia ("Hand-Foot" Syndrome). Annals of Oncology, 18, 1159-1164. https://doi.org/10.1093/annonc/mdl477

[20] Huober, J., Fett, W., Nusch, A., Neise, M., Schmidt, M., Wischnik, A., Gerhardt, S., Goehler, T., Lück, H.J. and Rost, A. (2010) A Multicentric Observational Trial of Pegylated Liposomal Doxorubicin for Metastatic Breast Cancer. BMC Cancer, 10, Article No. 2. https://doi.org/10.1186/1471-2407-10-2

[21] Pivot, X., Asmar, L., Buzdar, A.U., Valero, V. and Hortobagyi, G. (2000) A Unified Definition of Clinical Anthracycline Resistance Breast Cancer. British Journal of Cancer, 82, 529-534. https://doi.org/10.1054/bjoc.1999.0958

[22] Goldhirsch, A., Winer, E.P., Coates, A.S., Gelber, R.D., Piccart-Gebhart, M., Thürlimann, B. and Senn, H.J. (2013) Panelmembers-Personalizing the Treatment of Women with Early Breast Cancer: Highlights of the St Gallen International Expert Consensus on the Primary Therapy of Early Breast Cancer 2013. Annals of Oncology, 24, 2206 2223. https://doi.org/10.1093/annonc/mdt303

[23] Khakoo, S., Georgiou, A and Chau, I. (2015) Clinical Trial End Points Relevant to Patients and Society for Rare Cancers. Journal of Clinical Investigation (London), 6, 599-612.

[24] http://evs..nci.nih.gov/ftp1/CTCAE/CTCAE_4.03_2010-06-14_QuickReference_8.5 $\underline{\mathrm{x} 11 . \mathrm{pdf}}$

[25] IBM Corp. (2013) IBM SPSS Statistics for Windows. Version 22.0. IBM, Armonk.

[26] Fabi, A., Ferretti, G., Salesi, N., Papaldo, P., Carlini, P., Ciccarese, M., Di Cocco, B., Cecere, F., Nardoni, C., Felici, A. and Cognetti, F. (2005) Can HER2 Overexpression Predict Response to Pegylated Liposomal Doxorubicin in Metastatic Breast Cancer Patients? Annals of Oncology, 16, 516-517. https://doi.org/10.1093/annonc/mdi078 
[27] Fiegl, M., Mlineritsch, B., Hubalek, M., Bartsch, R., Pluschnig, U. and Steger, G.G. (2011) Single-Agent Pegylated Liposomal Doxorubicin (PLD) in the Treatment of Metastatic Breast Cancer: Results of an Austrian Observational Trial. BMC Cancer, 11, 373. https://doi.org/10.1186/1471-2407-11-373

[28] Basso, U., Roma, A., Brunello, A., Falci, C., Fiduccia, P., Banzato, A., Bononi, A., Gusella, M., Vamvakas, L., Zagonel, V. and Monfardini, S. (2013) Bi-Weekly Liposomal Doxorubicin for Advanced Breast Cancer in Elderly Women ( $\geq 70$ Years). Journal of Geriatric Oncology, 4, 340-345. https://doi.org/10.1016/j.jgo.2013.07.004

[29] Harbeck, N., Saupe, S., Jäger, E., Schmidt, M., Kreienberg, R., Müller, L., Otremba, B.J., Waldenmaier, D., Dorn, J., Warm, M., Scholz, M., Untch, M., de Wit, M., Barinoff, J., Lück, H.J., Harter, P., Augustin, D., Harnett, P., Beckmann, M.W., Al-Batran, S.E. and PELICAN Investigators (2017) A Randomized Phase III Study Evaluating Pegylated Liposomal Doxorubicin versus Capecitabine as First-Line Therapy for Metastatic Breast Cancer: Results of the PELICAN Study. Breast Cancer Research and Treatment, 161, 63-72. https://doi.org/10.1007/s10549-016-4033-3

\section{Abbreviations}

$A B C$ : advanced breast cancer

CBR: clinical benefit rate

CIs: confidence intervals

CK 5/6: cytokeratin 5/6

CR: complete response

CTCAE: Common Terminology Criteria for Adverse Events

ECOG: Eastern Cooperative Oncology Group

EGFR: epidermal growth factor receptors

Er: estrogen receptors

Her2: human epidermal growth factor receptor 2

HRs: hazard ratios

IDC: invasive ductal carcinoma

ILC: infiltrating lobular carcinoma

OS: overall survival

PFS: progression-free survival

PLD: pegylated liposomal doxorubicin

PPE palmar-plantar erythrodysesthesia

PR: partial response

Pr: progesterone receptors

SD: stable disease 